\title{
LEPMIDA Verbal Communication Strategy in Establishing Cooperation with the Local Government
}

\author{
Erica Septiana Anggelia \\ Communication Department \\ Bina Nusantara University \\ Jakarta, Indonesia \\ anggelia.erica@gmail.com
}

\author{
Nadira Kinanti Sadmoko \\ Communication Department \\ Bina Nusantara University \\ Jakarta, Indonesia \\ narasadmoko@gmail.com
}

\author{
La Mani \\ Communication Department \\ Bina Nusantara University \\ Jakarta, Indonesia \\ la.mani@binus.edu
}

\begin{abstract}
The research aims to describe the verbal communication strategies used by LEPMIDA in doing partnership with the local governments. The research is done by qualitative approach about communication relation case between LEPMIDA with local governments. Data collection is carried out by observation and interviews. The results showed that LEPMIDA verbal communication is by using email blast, sms blast, faxmile, social media, follow up and face to face, mouth to mouth, and also by joining the exhibition held by the Government which is attended by some large regional representatives in Indonesia. LEPMIDA consider that verbal communication is more effective in order to achieve the goal. LEPMIDA also implement a strategy to establish a good relationship with the local government by means of maintaining communications. However, in the implementation of the communication strategy of verbal LEPMIDA there are obstacles that interfere with the process of its implementation, such as the database error and the difficulties in finding the right key person of each regional representatives.
\end{abstract}

\section{Keywords: Strategy, Verbal Communication, Partnership}

\section{INTRODUCTION}

Indonesia is an archipelago consists of 34 provinces, 93.415 Counties and Cities. As a country of democracy and wide-scale, Indonesia embraces a regional autonomy principle vast autonomous region that is carried out by the Government alone on each region. According to the Law No. 32 of the year 2004, the autonomous region is the understanding of the rights, authority, and obligation of autonomous regions to manage and to oversee various things related to Government and the interests of its people in accordance with the applied legislation. In this case, the company sees an opportunity to establish a cooperation with the local governments. One of the companies that catches the opportunities is the Vibiz Group.

Vibiz Group is engaged in consulting services and as a partner in the development of the client by means of training, research, and business development organizations, and business consulting services. LEPMIDA as one of the Vibiz Group sub-division is an independent consulting agency in the field of establishment and development of Human Resources, Investation Startegy, Mediation with the investor, Community Development, Regional Promotion, and Regional Assets.

LEPMIDA has the commitment to carry out the job based on the standards of professionalism and integrity while upholding the code of ethics to work as a consultant. LEPMIDA has a number of experts in their fields, respectively, both with backgrounds of academics and experienced professionals. LEPMIDA has a network of employment in terms of technical institutions in the country and abroad, both Government and private universities are ready to provide the best service to its clients, in particular in implementing some of the activities in the Government. LEPMIDA was established to provide professional services to help the Government in the region with a focus to the development the quality management of Government related to the autonomy of the region, including in increasing the investment in the region.

The cooperation is carried out by the Government and is one of the training activities carried out with the aim to be able to develop the supremacy of each region. In the activities of this partnership deals there are some obstacles caused by distance, space, and time that give some difficulties to directly approach each local government. Therefore, to look more deeply about the applicability of verbal communication in favor of the success of the company to establish a partnership with the local government then author is interested in taking one of the private companies as an object research which is LEPMIDA.

\section{RESEARCH METHODOLOGY}

This study is using a qualitative approach. Qualitative research is a research procedure that seeks to generate descriptive data in the form of words or oral of people and the behavior observed from them. This qualitative research is using perspective data collection perspective such as detailed story of the informant. The location of the research is conducted at the Head Office of the company of Vibiz Group LEPMIDA Agung Podomoro Land Tower 9th Floor Central Park-Podomoro City. The technique of this data collection was done through in-depth interviews to the informant. Informants are determined purposively in research about LEPMIDA i.e. Management executive director, training manager and business manager. Data obtained from the results of the interviews were organized, analyzed and interpreted until it reaches the final conclusions.

\section{RESULT AND DISCUSSION}

LEPMIDA as private companies must have some supremacy and advantages compared to other companies so that it can successfully establish the cooperation with local governments. Based on the results of the research, LEPMIDA has what it takes so that the local Governments finally chose to follow the training that is held by the LEPMIDA as a private 
party, compared to other training institutions. Therefore, LEPMIDA is committed to become the organizer of the training that has a responsibility to produce a good quality output. In addition, LEPMIDA also have some teachers who are competent in their jobs, both in theoritic or practice.

In operational work, LEPMIDA is also supported by a team of internal staff to maintain the quality of the organization by following some communication skill trainings and some other trainings that will support the quality of the LEPMIDA team whenever the team has to communicate with the local governments. Therefore, the team of LEPMIDA has owned the skills on how to communicate in a professional way and also to produce knowledge about training that will be held by LEPMIDA. Later in this study, there are also some uniqueness of LEPMIDA organization in how they do the partnership with local governments, which is by providing convenience to the local governments to determine the time of implementation of the activities of how the training will be done. The implementation of the cooperation, which was held in the form of training is determined jointly between the LEPMIDA and local governments, is an opportunity that was given to local authorities to draw up a schedule that has some training terms i.e. representatives from area are available at least as many as five personel

Implementation of training organised by the LEPMIDA not only held on one area alone, but rather held in several large cities in Indonesia such as in Jakarta, Batam, Denpasar, Semarang and Yogyakarta. The purpose of the implementation of different training place is to provide options that make it easier for local governments, for example local authorities from Papua will be closer to Bali than heading to Jakarta. Furthermore, different venues give the variation of atmosphere for local governments that are still in the process of cooperation which held more than one time. So the implementation of the next cooperation can be held in a different city. So based on the above discussion, the excess of which is owned by LEPMIDA makes local governments throughout Indonesia choose to cooperate with LEPMIDA.

\section{A. LEPMIDA Communication Strategy Mechanism}

The mechanism of communication strategy is basically is a planning process (planning) and management (management) to accomplish one goal. LEPMIDA have planned a strategy in order to achieve the goal i.e work together with the local Government to conduct training. Verbal communication strategy used for disseminating the training program held by LEPMIDA towards the local governments is by implementing the follow-up which is contacted via phone and by speaking directly with the local governments after previously doing the first meeting.

In addition, the communication strategy used by LEPMIDA to carry out cooperation with local governments is to follow many exhibitions held by the local authorities for example Indonesia Investment Exhibition Week which participants are the entire provinces in Indonesia. Therefore, by following such activities aims to establish direct communication, mouth to mouth and face to face so that the LEPMIDA can build relationships or direct relationship with local governments. Strategy by doing follow-up and follow the activities of this exhibition is a form of oral communication strategy due to direct interaction between LEPMIDA with local governments. In addition, LEPMIDA also uses the communication by sending "sms blast" which contains an invitation about when the training will be held, blast email containing the proposal offer schedule training and then deploy social media usage information on information that will also be held.

Through this verbal communication strategies used by LEPMIDA is to use an email blast, sms blast, faxmile, social media usage, phone (follow up) and also through face to face, mouth to mouth, and also by following the exhibition held by the Government attended by most of the representative areas in Indonesia.

In the communication, there is a component which aims to solidify the process of the communication strategy. In order to solidify the communication strategy, all things must also be attributed with components that are the answers to the question in the formula of Lasswell i.e. the Who (as the communicator), Says what (message alleged), In which channel (what media is used), To whom (who communicate it) and With what effect (the effect of what was expected).

The communications component of LEPMIDA itself is started with the "Who" as the communicator. LEPMIDA party is an institution engaged in the service under the auspices of the Vibiz Group, then "Says what" is the message revealed by LEPMIDA as an offer of cooperation to conduct training. Then the channel in which the medium is used is electronic media such as telephone and fax. Next is to whom as the communicator in LEPMIDA. The communication components are local governments throughout Indonesia.

The communication also has a function that is disseminating information that is informative, persuasive and instructive systematically to target in order to obtain optimal results that is also serves closely with verbal communication strategies that is performed by LEPMIDA, disseminate information that is informative, persuasive and instructive regarding the training that will be implemented to gain cooperation with the local government in Indonesia. In carrying out the required LEPMIDA communication approaches to prospective customer i.e. local governments to facilitate the smooth implementation of the communication that is already designed. LEPMIDA is approaching with a way to make online media articles regarding potential areas that will be installed in beritadaerah.co.id as one of the divisions of news media under the auspices of the Vibiz group.

The purpose of the creating this online media articles is to develop the Government's awareness and to feel the seriousness of the LEPMIDA to explore the potential of the regional government because LEPMIDA will do the cooperation with the authorities of the area before studying the potential owned by the area. Another approach is done by building relationships by sending words of motivation through SMS. This shows that LEPMIDA is caring about the local government so that local governments still feel cared for, although cooperation already done but LEPMIDA will still keep the communication. Furthermore LEPMIDA want the Government to feel the seriousness of the LEPMIDA to implement such cooperation.

Later on, the approaches that is done next is to directly build relationships via telephone and SMS also. Through this 
approach that is carried out by LEPMIDA, the purpose is to immediately know the desires and problems of local government.

B. Development, Obstacles, and Solutions Faced by LEPMIDA

LEPMIDA is an agency that has been running nearly eleven years, in the journey of this eleven years, LEPMIDA experience the development of a strategy for cooperation with local governments.

At the beginning of the establishment, LEPMIDA is using a mechanism that is relying on one person's as a key person of each regional representative who can be contacted. However later, this is considered quite ineffective because the plan did not work out good because not all of the local governments have a key person.

This led to the planned creation of a new verbal communication strategies based on the situation and the current conditions in the hope of a strategy used currently being more effective and beneficial. The development of this mechanism is done by performing a database update, so LEPMIDA always get a key person of each local government.

In the communications made by the company often occurs some obstacles that interfere with the process of the implementation of the plan that has been designed. Obstacles that normally occur is claimed by Cangara (2006) as the following technical disruption. Technical interruption occurs if any of the tools used in communicating experience interference, which makes information sent over a communications channel suffering from a damage.

Semantic and psychological disorders. Semantic communication disorder is a disorder caused by an error in the language. Physical obstacles. Physical obstacles due to geographical conditions, for example a distance that is difficult to achieve. Barrier status. Barrier status due to social distance communication among the participants. Barrier frame. Obstacles frame caused by the difference in perception between the communicators towards the messages that is communicated. Cultural obstacles. Cultural obstacles caused by the difference in the difference of norms, routines and values.

Based on the results of this research, it is noted that the technical disruptions in the implementation of this communication is (1) the contact person of the key person of each local government that is not appropriate and not obtained by the LEPMIDA thus causing the LEPMIDA incapable of delivering the right information to the government, (2) problems in the communication network also interfere with the implementation of the communication strategy and causing it to not running smoothly. This poor communication network is becoming the "noise" in the communication process that is in progress, (3) database error that is also obtained also become one of the barriers to the implementation of the communication strategy that has been made because this database error creates information that should be delivered.

The obstacles faced by LEPMIDA resulted in the disruption of the process of verbal communication in processing the communication that has been planned.
Therefore LEPMIDA is planning the right solution to address the barriers that interfere with the process of communication strategy. According to informants of this study, there are several solutions that can be used to search the database, such as (1) by updating the database on a regular basis, this is because of government staff is usually mutated so that key person on each of the area is changing regularly. Therefore, it is very important to continuously renew the database owned by the LEPMIDA, (2) bu visiting the area to conduct activities to offer the cooperation directly. and (3) by conducting evaluation of process so that LEPMIDA can maintain and observe the developments and LEPMIDA can also continue to control the running processes whether it is already running according to the plan or if it is not yet running smoothly then LEPMIDA will try to find the right solution for it.

Based on the above description, there are some solutions that have been prepared and carried out by LEPMIDA to overcome the obstacles, hopefully LEPMIDA can immediately find a solution so that the communication strategy can run properly and also the purpose of the LEPMIDA to conduct cooperation with local governments may be achieved.

The results of the research on verbal communication used by LEPMIDA is related to Berger's theory of Planning and Goals in which there is a link between this theory with the discussion of this research. Berger's theory of Planning and Goals explains that the role of cognitive structure in the production of messages and wishes are various. Planning and Goals explaining the existence of planning is very important in determining the wishes that will be achieved in communication itself.

The development of the production theory of this message is to consider planning and goals. This theory provides a framework about understanding the cognitive structures and how they affect the structure of verbal and nonverbal behavior. According to Berger in (Miller, 2005) conceptions regarding the "goals and plans" often done to explain how to understand other people's behaviours and actions of symbolist in the narrative text. Berger's Theory Planning gives an explanation of how plans are made and formulated. Theory of Planning in the field of communication created by Charles Berger is to explain the process of the individual planning in their communication behavior (Littlejohn, 2008).

Planning is the process of thinking up a plan of action, because communication is very important to achieve the goals. Theories that depart from the social psychology can also describe the processes that take place in man in the communication process i.e. during the process of creating messages and process understanding the message. Humans in the process of generating a message involves a process that is taking place internally in man such as the process of thinking, decision making, and the process of using symbols. Similarly, in the process of understanding the messages received, people also use psychological processes such as thinking, understanding, using short and long term memories to make a definition. The process of human communication is a process which takes place in man himself.

Based on the explanation of Berger's theory of Planning and Goals which stated that the existence of message planning 
is very important in determining the goals that would like to be accomplished. This theory is relevant to the study of verbal communication which will be used by LEPMIDA in determining and implementing the function, in which LEPMIDA always make planning in building a partnership with the local government.

\section{CONCLUSION}

Through this verbal communication strategies used by LEPMIDA is to use an email blast, sms blast, faxmile, social media usage, phone (follow up) and also through face to face, mouth to mouth, and also by following the exhibition held by the Government attended by most of the representative areas in Indonesia.

The obstacles faced by LEPMIDA resulted in the disruption of the process of verbal communication in processing the communication that has been planned. Therefore LEPMIDA is planning the right solution to address the barriers that interfere with the process of communication strategy. According to informants of this study, there are several solutions that can be used to search the database, such as (1) by updating the database on a regular basis, this is because of government staff is usually mutated so that key person on each of the area is changing regularly. Therefore, it is very important to continuously renew the database owned by the LEPMIDA, (2) bu visiting the area to conduct activities to offer the cooperation directly. and (3) by conducting evaluation of process so that LEPMIDA can maintain and observe the developments and LEPMIDA can also continue to control the running processes whether it is already running according to the plan or if it is not yet running smoothly then LEPMIDA will try to find the right solution for it.

LEPMIDA has some advantages over other institutions such as professional lecturers either in theoritic or practice. In addition LEPMIDA also has some advantages i.e. ownership of internal communication skill trainer and several other trainings that will support the quality of LEPMIDA team at a time when they create the communication with local governments. Verbal communication strategies used at this time is already in the right way, but it does not close the possibility that in the future there will be a new communication mechanisms that will be used by the LEPMIDA along with the dynamics of social and the economy, as well as the development of technology and information.

\section{REFERENCES}

[1] Cangara, Hafied, (2006). Pengantar Ilmu Komunikasi, Edisi I. Jakarta: PT Raja Grafindo Persada.

[2] Effendy, Onong Uchjana, (2013). Ilmu Komunikasi Teori dan Praktek. Bandung: PT Remaja Rosdakarya.

[3] Miller, Katherine (2005). Communication Theories: Perspective.

[4] Littlejohn, Stephen W, Karen A Foss., (2008). The Theories of Human Communication, Edisi 9.

[5] Prisgunanto, Ilham. (2006). Komunikasi Pemasaran: Strategi dan Taktik. Bogor: Ghalia Indonesia.

[6] Sugiyono. (2009). Metode Penelitian Bisnis. Bandung: Alfabeta. 